\title{
The Past, Present and Future of Immunotherapy for Metastatic Renal Cell Carcinoma
}

\author{
ALEXANDER J. CHANG ${ }^{1 *}$, LEI ZHAO ${ }^{2 *}$, ZIWEN ZHU ${ }^{3}$, KYLE BOULANGER $^{1}$, \\ HUAPING XIAO ${ }^{1,4}$, MARK R. WAKEFIELD ${ }^{3}$, QIAN BAI ${ }^{3}$ and YUJIANG FANG ${ }^{1,3}$ \\ ${ }^{1}$ Department of Microbiology, Immunology \& Pathology, Des Moines University, Des Moines, IA, U.S.A.; \\ ${ }^{2}$ The Department of Respiratory Medicine, The 2nd People's Hospital of Hefei and \\ Hefei Hospital Affiliated to Anhui Medical University, Hefei, P.R. China; \\ ${ }^{3}$ Department of Surgery, University of Missouri School of Medicine, Columbia, MO, U.S.A.; \\ ${ }^{4}$ The Affiliated Hospital of Xiangnan University, Chenzhou, P.R. China
}

\begin{abstract}
The treatment of renal cell carcinoma (RCC) has evolved tremendously over the past decades. Localized disease is often curative with surgical resection of the malignancy. However, in cases where the primary tumor has metastasized, immunotherapy is becoming a more prevalent means to combat metastatic renal cell carcinoma ( $m R C C)$. Cytokine and checkpoint inhibitor immunotherapy have been demonstrated to stimulate the immune response through a number of different mechanisms. These drugs have been used as a monotherapy, combination therapy, or as successive treatments to systemic therapies. This review summarizes the success of previous and current therapeutic targets, while also leading to the direction of future therapies. This review might be helpful in improving the management of $m R C C$.
\end{abstract}

Renal cell carcinoma is the most common malignancy of the kidney, comprising 2-3\% of all cancers in adults, and the seventh leading cause of cancer in men and ninth in women (1). At the time of diagnosis, it is estimated that $25 \%$ of patients will have a metastatic disease; anywhere from $20 \%$ to $50 \%$ will develop metastatic disease after surgical intervention and will require systemic therapy (2). Immunotherapy is an increasingly popular and studied treatment modality that utilizes the body's own immune system to combat metastatic

*These Authors contributed equally to this study.

Correspondence to: Dr. Yujiang Fang, Department of Microbiology, Immunology \& Pathology, Des Moines University College of Osteopathic Medicine, Des Moines, Iowa 50312, U.S.A. Tel: +1 5152711435, Fax: +1 5152711543, e-mail: yujiang.fang@dmu.edu

Key Words: Cytokine, renal cell carcinoma, review. cancer. Advancements in biotechnology and knowledge of molecular targets have expanded the arsenal available to urologists to treat metastatic renal cell carcinoma (mRCC).

\section{Cytokine Immunotherapy}

Interleukin-2 (IL2). IL2 has been a standing immunotherapy for mRCC since the early 1990s. As a native cytokine in the human body, its role in immunity encompasses aspects of both innate and adaptive immunity. Specifically, IL2 has been shown to activate natural killer cells and promote CD8+ T cell maturity. Indeed, these are important in mounting an immune response to foreign pathogens but its use as a monotherapy for mRCC has shown limited success with curative rates in approximately $8 \%$ of patients (3). In the remainder of patients who received IL2 therapy, the median overall survival was found to be 15.8 months. One of the limiting factors of monotherapy with IL2 is treatment-associated toxicity. Thus, in an effort to improve clinical outcomes and minimize adverse effects, IL-2 has largely been studied in combination with a variety of different therapies.

A combination of IFN- $\alpha$, IL2, and 5-fluorouracil (5-FU) had a greater response rate than IL2 alone, with $48 \%$ of patients responding to the treatment (4). However, the response to therapy seen with this combination was not confirmed in subsequent studies (5). One of the most striking benefits of IL2 is its ability to induce long lasting abatement of mRCC. Long-term survival was studied in patients who received IL2 therapy, and $10-20 \%$ of patients remained alive 5 to 10 years after treatment (6).

Interferon- $\alpha(I F N-\alpha)$. IFN- $\alpha$ is another endogenous cytokine commonly used in the treatment of Hepatitis C. Its efficacy as a systemic therapy against malignancy has 
been extensively studied in a variety of cancers including mRCC. IFN- $\alpha$ is thought to act on T-cells and dendritic cells to induce its antitumor effects. Earlier studies on recombinant IFN- $\alpha$ treatment have shown response rates averaging $15 \%$ for 4 to 6 months with a complete response rate $\leq 5 \%$. Similar to IL2 monotherapy, doserelated toxicities remain a limiting factor in the use of IFN- $\alpha$ as therapy. Additional studies of IFN- $\alpha$ monotherapy have shown what appears to be a similar outcome profile to IL2: a small proportion of patients achieve long-term survival (7).

The pursuit of combination therapy of IFN- $\alpha$ with the vinca alkaloid vinblastine was not more effective than monotherapy, with a modest survival benefit of three to seven months in the treatment group (8). Another investigation of IFN- $\alpha$ with bevacizumab showed that the combination was superior to monotherapy with IFN- $\alpha$. Progression-free survival in this study was found to be 10.2 months in the treatment group compared to 5.4 months in the control group (9). Researchers should continue to investigate the efficacy of IL2 and IFN- $\alpha$ using different drug combinations. The primary conclusion that can be drawn from monotherapy with the immune-modulating cytokines IFN- $\alpha$ and IL2 is that they remain viable options for a small subset of patients; more extensive research is needed into the parameters of this subset. It is likely that this subset of patients is dependent upon specific prognostic factors. Most importantly, these data underscore the need for a more encompassing therapy with a minimal side effect profile and longevity.

\section{Checkpoint Inhibitor Immunotherapy}

The ability to evade immune surveillance and programmed cell death is a primary mechanism to cancer's insidious success (10). Various tumors may express biomarkers that prevent the body from mounting an immune response. Indeed, this is critical to the body's regulation of preventing cells with damaged nuclear content from proliferating. It is well known that cell division is arrested upon sustained cellular damage to allow repair. When repair is not possible, cell death is induced to prevent the development of a renegade cell line. Restoring the ability of the immune system to function through its various checkpoints is an area of particular interest. T-regulatory cells are hypothesized to play a large role in the regulation of the T-cell response and what the body recognizes as "self" or "foreign" (11). CTLA-4 and PD-1 are such inhibitory receptors that are of molecular interest. A plethora of drugs within this class have been developed, studied, and currently marketed for use as effective therapies in the treatment of $\mathrm{mRCC}$ and numerous other malignancies.

\section{CTLA-4}

Ipilimumab and tremelimumab are two monoclonal antibodies that act on the inhibitory molecule CTLA-4. CTLA-4, also called CD15, is found on T-cells and, when activated, results in the inhibition of T-cell function. Ipilimumab is an $\mathrm{IgG} 1$ isotype that has been investigated in clinical trials in patients who previously received IL-2 therapy or were ineligible. The study was set up in two groups with one receiving low dose ipilimumab (initial 3 $\mathrm{mg} / \mathrm{kg}$ followed by $1 \mathrm{mg} / \mathrm{kg}$ ) and the other receiving high dose ( $3 \mathrm{mg} / \mathrm{kg}$ every three weeks). Treatment was found to induce autoimmune events (e.g. enteritis and hypophysitis) in 17 patients in a cohort of 40 . Of note is the direct correlation between tumor regression and autoimmune events. Of those who sustained responses, $30 \%$ had an autoimmune event compared to $0 \%$ response with no autoimmune event (12). It is clear that further investigation into attenuating autoimmune events with ipilimumab treatment will be crucial to its efficacy in mRCC therapy.

Different from ipilimumab, which is an IgG1 isotope, tremelimumab is an IgG2 isotope. Tremelimumab has been trialed in $\mathrm{mRCC}$ with sunitinib, a tyrosine kinase inhibitor that acts on the vascular endothelial growth factor (VEGF) receptor. The combination was used in lieu of monotherapy based on the hypothesis that the combination would have additive or synergistic activity. It was found that this combination elucidated a durable response only in 9 of 21 patients (43\%) (13). Clearly, the lower durable response to this combination therapy of tremelimuma and sunitinib suggests that more research into this combination and dosing is required to limit the adverse effects and optimize treatment. Furthermore, it may be prudent to investigate the effects of tremelimumab alone or with other immunomodulating drugs for possible success in the treatment of mRCC.

\section{PD-1 Inhibitors}

Similar to CTLA-4, PD-1 is also a receptor that is responsible for the down-regulation of T-cells. Evidence supports a poor prognosis for tumors that are found to express the PD1 receptor (14). Thus, therapy targeted towards inhibition of PD1 receptor activation may result in partial or durable responses.

Nivolumab is one such therapy that shows promise in its ability to treat mRCC. It acts to inhibit interaction between PD-1 and its ligands PD-L1 and PD-L2 (15). Results of one study showed a $20 \%-22 \%$ response rate in patients with improved overall and progression-free survival durations. Specifically, more responses were noted in patients whose PD-L1 expression (>5\%) was quantifiably higher, but those with a lower expression still benefited from the treatment 
(16). All patients in the phase II study of nivolumab also received previous treatment with another targeted agent or cytokine therapy. Importantly, nivolumab also demonstrates an acceptable and comparable safety profile across doses of $0.3,2$, and $10 \mathrm{mg} / \mathrm{kg}$ (17).

A subsequent phase III study of nivolumab compared to everolimus, a mammalian target of rapamycin (mTOR) inhibitor, demonstrated longer overall survival (5.4 months) and fewer high-grade adverse events. Thus, there is evidence that supports the use of nivolumab in the treatment of patients with advanced mRCC (18).

Pembrolizumab is another PD-1 inhibitor that has been studied in conjunction with axitinib, a VEGFR inhibitor. Preliminary studies have shown that this combination's safety profile and efficacy warrant further study. Of note is its success in patients who have not received previous therapy for mRCC. It would be worth investigating whether previous therapy would alter the safety and benefit profile of treatment.

\section{PD-L1 Inhibitors}

PD-L1 inhibitors act in a similar fashion to PD-1 inhibitors except that they target the ligand as opposed to the receptor. Atezolizumab is a PD-L1 inhibitor that has shown success in Phase I clinical trials. Patients were screened prior to therapy to assess for biomarkers that could be associated with response to atezolizumab. In addition to its safety profile and ability to induce antitumor response, a decrease in circulating VEGFA was noted in patients responding to atezolizumab (19). A subsequent study of bevacizumab combined with atezolizumab showed promise in its ability to induce antitumor response with an acceptable side effect profile. This combination yielded a remarkable $40 \%$ response rate- greater than either monotherapy. It appears that this combination results in an increase in T-cell response to mRCC (20).

The study of atezolizumab alone has yielded the possibility of a cost-effective and straightforward objective measure of tumor response. Further studies are necessary to understand atezolizumab's clinical role in the treatment of mRCC and the sensitivity and specificity of measuring VEGFA for tumor response. Furthermore, the combination of atezolizumab with bevacizumab has shown that combination therapy is an area of growing interest. However, this therapy is likely to be more successful in patients who express specific biomarkers. It is also possible that the combination of PD-1 and PD-L1 inhibitors may yield additive or synergistic response; this would require careful study and consideration.

\section{VEGF Inhibitors}

Vascular endothelial growth factor (VEGF) is thought to play a critical role in tumor angiogenesis. As another hallmark of cancer, angiogenesis is understood to play a crucial role in tumorigenesis (8). An increase in tumor mass correlates with an increase in nutrients required to sustain the high metabolic demand of constantly proliferating cells. Although VEGF participates in normal body processes such as development, repair, and growth, tumor utilization of VEGF signaling has catastrophic results. Thus, VEGF inhibition to limit tumor proliferation and deprive renegade cells of nutrients is of particular interest.

Bevacizumab is classified as a VEGF inhibitor and has been previously discussed for its use in combination therapy of mRCC. Sorafenib is another such inhibitor that has been studied in the treatment of mRCC. It was found in a phase III trial that monotherapy with sorafenib resulted in a survival advantage when compared to the control group. Furthermore, this study iterates VEGF as a prognostic indicator for treatment with VEGF inhibitors (21). As with atezolizumab, VEGF may also be useful to measure therapeutic responsiveness. Another VEGF inhibitor is sunitinib, which was shown to have longer progression-free survival and response rates than patients who received IFN$\alpha$ for the treatment of mRCC. Furthermore, quality of life was also compared in this study, which was shown to be higher in the sunitinib group (22).

VEGF inhibition has shown a beneficial profile in the treatment of mRCC both in combination and as a monotherapy. The ability to use VEGF levels as a measurement to predict and measure responsiveness is of particular interest and should be an area of continued study.

\section{Future of Cytokine and Checkpoint Inhibitor Immunotherapy}

The future of immunotherapy in the treatment of renal cell carcinoma is dependent on several different factors. While great progress has been made and responses have been achieved, many of these clinical successes remain in a subset of the treated population. Many of these therapies are successful in patients with good prognostic factors or in those who express specific biomarkers that predict drug responsiveness. This understates the likelihood that pharmacogenomics and molecular analysis of individual patient's tumors will be critical elements to successful immunotherapy. Furthermore, recognition of a measurable serum value to follow tumor responsiveness should be sought out. This will help clinicians recognize when to continue therapy, maximize dosing for clinical response, or discontinue therapy and pursue another avenue.

Much of the future of immunotherapy will also depend on the progress of biotechnology and our ability to synthesize molecules capable of being delivered to and acting on their intended target. This will also be paralleled by our growing knowledge of the immune system and molecular targets. 
Drug toxicity is also of paramount concern. Limiting drug toxicity while maximizing therapeutic effect must perpetually be pursued. This may be done by combining lower doses of multiple different therapies or adding adjunctive non-therapeutic drugs with the intent of palliating side effects. This author believes that combination therapy will be an area of growing interest. It appears that stimulation of multiple aspects of the immune system is more likely to result in therapeutic responses. Additionally, induction therapy with one systemic agent before application with another requires more investigation.

Quality of life for those receiving immunotherapy must also be evaluated. Progression-free survival and responsiveness are important measures of therapy, but their usefulness as measures of success should not overshadow individual quality of life. A standardized measure of quality of life using the Functional Assessment of Cancer TherapyGeneral (FACT-G) can be utilized in studies to more comprehensively assess the effect of cancer immunotherapy (23). It is important to elicit an individual patient's goals of treatment before therapy, to continue to evaluate those goals as therapy continues, and bear them in mind after cessation of therapy.

\section{Conflicts of Interest}

The Authors have no conflict of interest.

\section{Authors' Contributions}

YF conceived this study. All Authors performed literature searches on PubMed. AJC, ZZ and YF drafted the manuscript. All Authors approved the final version of the manuscript.

\section{Acknowledgements}

This study was supported by grants for Yujiang Fang (Iowa Science Foundation Grant ISF 16-8, IOER 05-14-01, IOER 112-3749 and IOER 112-3104).

\section{References}

1 Rini BI, Campbell SC and Escudier B: Renal cell carcinoma. Lancet 373(9669): 1119-1132, 2009. PMID: 19269025. DOI: 10.1016/S0140-6736(09)60229-4

2 Flanigan RC, Campbell SC, Clark JI and Picken MM: Metastatic renal cell carcinoma. Curr Treat Options Oncol 4(5): 385-390, 2003. PMID: 12941198. DOI: 10.1007/s11864-003-0039-2

3 Sathianathen NJ, Krishna S, Anderson JK, Weight CJ, Gupta S, Konety BR and Griffith TS: The current status of immunobased therapies for metastatic renal-cell carcinoma. Immunotargets Ther 6: 83-93, 2017. PMID: 29255699. DOI: 10.2147/ITT.S1 34850

4 Atzpodien J, Kirchner H, Hanninen EL, Deckert M, Fenner M and Poliwoda $\mathrm{H}$ : Interleukin-2 in combination with interferon- alpha and 5-fluorouracil for metastatic renal cell cancer. Eur $\mathbf{J}$ Cancer 29A: S6-8, 1993. PMID: 8260264. DOI: 10.1016/09598049(93)90617-O

5 van Herpen CM, Jansen RL, Kruit WH, Hoekman K, Groenewegen $\mathrm{G}$, Osanto $\mathrm{S}$ and De Mulder PH: Immunochemotherapy with interleukin-2, interferon-alpha and 5-fluorouracil for progressive metastatic renal cell carcinoma: A multicenter phase ii study. Dutch immunotherapy working party. Br J Cancer 82(4): 772-776, 2000. PMID: 10732744. DOI: 10.1054/bjoc.1999.0997

6 Fisher RI, Rosenberg SA and Fyfe G: Long-term survival update for high-dose recombinant interleukin-2 in patients with renal cell carcinoma. Cancer J Sci Am 6: S55-57, 2000. PMID: 10685660 .

7 Motzer RJ, Bacik J, Murphy BA, Russo P and Mazumdar M: Interferon-alfa as a comparative treatment for clinical trials of new therapies against advanced renal cell carcinoma. J Clin Oncol 2O(1): 289-296, 2002. PMID: 11773181. DOI: 10.1200/ JCO.2002.20.1.289

8 Fossa SD: Interferon in metastatic renal cell carcinoma. Semin Oncol 27(2): 187-193, 2000. PMID: 10768597.

9 Escudier B, Pluzanska A, Koralewski P, Ravaud A, Bracarda S, Szczylik C, Chevreau C, Filipek M, Melichar B, Bajetta E, Gorbunova V, Bay JO, Bodrogi I, Jagiello-Gruszfeld A, Moore $\mathrm{N}$ and investigators AT: Bevacizumab plus interferon alfa-2a for treatment of metastatic renal cell carcinoma: A randomised, double-blind phase iii trial. Lancet 370(9605): 2103-2111, 2007. PMID: 18156031. DOI: 10.1016/S0140-6736(07)61904-7

10 Hanahan D and Weinberg RA: Hallmarks of cancer: The next generation. Cell 144(5): 646-674, 2011. PMID: 21376230. DOI: 10.1016/j.cell.2011.02.013

11 Okazaki T, Iwai Y and Honjo T: New regulatory co-receptors: Inducible co-stimulator and pd-1. Curr Opin Immunol 14(6): 779-782, 2002. PMID: 21376230. DOI: 10.1016/S09527915(02)00398-9

12 Yang JC, Hughes M, Kammula U, Royal R, Sherry RM, Topalian SL, Suri KB, Levy C, Allen T, Mavroukakis S, Lowy I, White DE and Rosenberg SA: Ipilimumab (anti-ctla4 antibody) causes regression of metastatic renal cell cancer associated with enteritis and hypophysitis. J Immunother 30(8): 825-830, 2007. PMID: 18049334. DOI: 10.1097/CJI.0 b013e318156e47e

13 Rini BI, Stein M, Shannon P, Eddy S, Tyler A, Stephenson JJ, Jr., Catlett L, Huang B, Healey D and Gordon M: Phase 1 doseescalation trial of tremelimumab plus sunitinib in patients with metastatic renal cell carcinoma. Cancer 117(4): 758-767, 2011. PMID: 20922784. DOI: 10.1002/cncr.25639

14 Escudier B: Emerging immunotherapies for renal cell carcinoma. Ann Oncol 23(Suppl 8): viii35-40, 2012. PMID: 22918926. DOI: $10.1093 /$ annonc/mds261

15 Cho YH, Kim MS, Chung HS and Hwang EC: Novel immunotherapy in metastatic renal cell carcinoma. Investig Clin Urol 58(4): 220-227, 2017. PMID: 28681030. DOI: 10.4111/ icu.2017.58.4.220

16 Motzer RJ, Rini BI, McDermott DF, Redman BG, Kuzel TM, Harrison MR, Vaishampayan UN, Drabkin HA, George S, Logan TF, Margolin KA, Plimack ER, Lambert AM, Waxman IM and Hammers HJ: Nivolumab for metastatic renal cell carcinoma: Results of a randomized phase ii trial. J Clin Oncol 33(13): 14301437, 2015. PMID: 25452452. DOI: 10.1200/JCO.2014.59.0703 
17 Topalian SL, Hodi FS, Brahmer JR, Gettinger SN, Smith DC, McDermott DF, Powderly JD, Carvajal RD, Sosman JA, Atkins MB, Leming PD, Spigel DR, Antonia SJ, Horn L, Drake CG, Pardoll DM, Chen L, Sharfman WH, Anders RA, Taube JM, McMiller TL, Xu H, Korman AJ, Jure-Kunkel M, Agrawal S, McDonald D, Kollia GD, Gupta A, Wigginton JM and Sznol M: Safety, activity, and immune correlates of anti-pd-1 antibody in cancer. N Engl J Med 366(26): 2443-2454, 2012. PMID: 22658127. DOI: $10.1056 /$ NEJMoa 1200690

18 Motzer RJ, Escudier B, McDermott DF, George S, Hammers HJ, Srinivas S, Tykodi SS, Sosman JA, Procopio G, Plimack ER, Castellano D, Choueiri TK, Gurney H, Donskov F, Bono P, Wagstaff J, Gauler TC, Ueda T, Tomita Y, Schutz FA, Kollmannsberger C, Larkin J, Ravaud A, Simon JS, Xu LA, Waxman IM, Sharma P and CheckMate I: Nivolumab versus everolimus in advanced renal-cell carcinoma. N Engl J Med 373(19): 1803-1813, 2015. PMID: 26406148. DOI: 10.1056/ NEJMoa1510665

19 McDermott DF, Sosman JA, Sznol M, Massard C, Gordon MS, Hamid O, Powderly JD, Infante JR, Fasso M, Wang YV, Zou W, Hegde PS, Fine GD and Powles T: Atezolizumab, an antiprogrammed death-ligand 1 antibody, in metastatic renal cell carcinoma: Long-term safety, clinical activity, and immune correlates from a phase ia study. J Clin Oncol 34(8): 833-842, 2016. PMID: 26755520. DOI: 10.1200/JCO.2015.63.7421

20 Wallin JJ, Bendell JC, Funke R, Sznol M, Korski K, Jones S, Hernandez G, Mier J, He X, Hodi FS, Denker M, Leveque V, Canamero M, Babitski G, Koeppen H, Ziai J, Sharma N, Gaire F, Chen DS, Waterkamp D, Hegde PS and McDermott DF: Atezolizumab in combination with bevacizumab enhances antigen-specific $\mathrm{t}$-cell migration in metastatic renal cell carcinoma. Nat Commun 7: 12624, 2016. PMID: 27571927. DOI: $10.1038 /$ ncomms 12624
21 Escudier B, Eisen T, Stadler WM, Szczylik C, Oudard S, Staehler M, Negrier S, Chevreau C, Desai AA, Rolland F, Demkow T, Hutson TE, Gore M, Anderson S, Hofilena G, Shan M, Pena C, Lathia C and Bukowski RM: Sorafenib for treatment of renal cell carcinoma: Final efficacy and safety results of the phase iii treatment approaches in renal cancer global evaluation trial. J Clin Oncol 27(20): 3312-3318, 2009. PMID: 19451442. DOI: $10.1200 / \mathrm{JCO} .2008 .19 .5511$

22 Motzer RJ, Hutson TE, Tomczak P, Michaelson MD, Bukowski RM, Rixe O, Oudard S, Negrier S, Szczylik C, Kim ST, Chen I, Bycott PW, Baum CM and Figlin RA: Sunitinib versus interferon alfa in metastatic renal-cell carcinoma. N Engl J Med 356(2): 115-124, 2007. PMID: 17215529. DOI: 10.1056/ NEJMoa065044

23 Cella DF, Tulsky DS, Gray G, Sarafian B, Linn E, Bonomi A, Silberman M, Yellen SB, Winicour P and Brannon J: The functional assessment of cancer therapy scale: Development and validation of the general measure. J Clin Oncol 11(3): 570-579, 1993. PMID: 8445433. DOI: 10.1200/JCO.1993.11.3.570
Received April 18, 2019

Revised May 22, 2019

Accepted May 23, 2019 